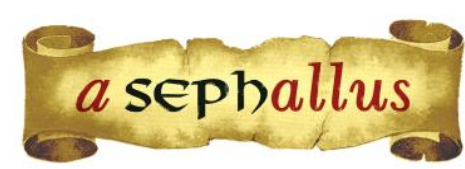

Revista aSEPHallus de Orientação Lacaniana

Núcleo Sephora de Pesquisa sobre o Moderno e o Contemporâneo

ISSN $1809-709 \mathrm{X}$

\title{
A clínica psicanalítica frente à demanda trans ${ }^{1}$
}

Esther Siza Tribuzy

Orcid: 0000-0002-8461-8793

Mestre em Psicologia pela Universidade Federal do Paraná / UFPR (Paraná, Brasil) Psicóloga do Centro de Pesquisas e Atendimentos a Travestis e Transexuais (CPATT) (Paraná, Brasil) e-mail: esthertribuzy@gmail.com

Rosane Zétola Lustoza

Orcid: 0000-0001-5299-4316

Doutora em Teoria Psicanalítica pelo Programa de Pós-Graduação em Teoria Psicanalítica da Universidade Federal do Rio de Janeiro / UFRJ (Paraná, Brasil)

Professora Associada do Programa de Pós-Graduação em Psicologia da Universidade Federal do Paraná / UFPR

(Paraná, Brasil)

e-mail: rosanezetola@gmail.com

Resumo: O objetivo deste trabalho é investigar a escuta psicanalítica numa instituição de saúde voltada para a população trans, tomando como central o conceito lacaniano de demanda. Busca-se uma definição do fenômeno trans que evite tanto a abordagem dos manuais classificatórios quanto as perspectivas em psicanálise que 0 atrelam a uma estrutura determinada. Propõe-se um trabalho com a demanda que vise localizar a função do processo transexualizador para cada sujeito. Conclui-se que o trabalho com a demanda visa a elaboração das condições subjetivas para que alguém possa sustentar as consequências do seu pedido de transição.

Palavras-chave: Transexualidade; Lacan; Demanda; Psicanálise em instituições.

The psychoanalytical clinic facing the trans demand: The aim of this paper is to investigate the psychoanalytic listening in a health institution focused on the trans population taking as central the lacanian concept of demand. We seek a definition of the trans phenomenon that avoid both the approach of the classification manuals and the perspectives on psychoanalysis that link it to a specific structure. We propose a work with the demand aimed at locating the function of the transsexualizing process for each subject. We conclude that work with the demand aims to develop subjective conditions so that someone can sustain the consequences of their transition 's request.

Keywords: Transsexuality; Lacan; Demand; Psychoanalysis in institutions.

La clinique psychanalytique face à la demande trans: L'objectif de ce travail est d'étudier l'écoute psychanalytique dans un établissement de santé centré sur la population trans, en prenant comme point central le concept lacanien de demande. Nous cherchons une définition du phénomène trans qui évite à la fois l'approche des manuels classificatoires et les perspectives en psychanalyse qui le lient à une structure déterminée. Il est proposé un travail auprès de la demande qui vise à situer la fonction du processus de transexualisation pour chaque sujet. On en conclut que le travail avec la demande vise à l'élaboration des conditions subjectives pour que quelqu'un puisse supporter les conséquences de sa demande de transition.

Mots clés: Transexualité; Lacan; Demande; Psychanalyse en institutions. 


\title{
A clínica psicanalítica frente à demanda trans
}

\author{
Esther Siza Tribuzy \& Rosane Zétola Lustoza
}

\section{Introdução}

O trabalho analítico com travestis e transexuais interroga diariamente a relação entre sexo biológico e identidade de gênero Observa-se aí um descolamento entre corpo e identidade, uma separação entre a anatomia do corpo e o modo como ele é tomado e representado. As vivências trans demonstram claramente que a construção de uma identidade masculina ou feminina não está necessariamente associada à genitália ou a qualquer característica sexual secundária. Fica claro, a partir do que se observa no trabalho realizado no CPATT (Centro de Pesquisa e Atendimento a Travestis e Transexuais - serviço destinado a receber essa população no Paraná), que ter um pênis não implica em ser homem e ter uma vagina não faz de alguém uma mulher. Verdade que, embora constatável em qualquer tratamento analítico, torna-se escancarada na clínica em exame, já que o fenômeno trans nos coloca diante da possibilidade de afirmar que existem homens com vaginas e mulheres com pênis.

Todavia, a questão da diferença sexual biológica não se reduz ao órgão genital; implica em diferenças físicas que vão muito além daquela. Percebe-se claramente que os traços do corpo e do rosto se moldam distintamente no macho e na fêmea do ser humano; a distribuição de pelos, de gordura e de músculo são indiscutivelmente heterogêneas em cada sexo. Ainda que tudo isso esteja posto, não podemos afirmar que haja a correspondência entre sexo e gênero, ou uma congruência entre corpo e identidade; o que nos permite observar a fragilidade da noção de unidade entre eu e corpo.

É comum encontrarmos em qualquer ser humano alguma queixa sobre o próprio corpo, bem como várias tentativas de se apaziguar com esse incômodo. Aquilo que nos parece marcar sua diferença com relação à maioria das pessoas é que as pessoas trans, em função de uma discrepância experimentada entre corpo e psiquismo, decidem começar o que se chama processo transexualizador. Tal processo abrange mudanças comportamentais e corporais, através de intervenções estéticas, tratamento hormonal e muitas vezes cirúrgico, graças aos quais as pessoas se submetem a alterações profundas na imagem do corpo, no intuito de se assemelharem ou passarem para o gênero ao qual sentem pertencer.

O objetivo deste trabalho é investigar qual a função da escuta orientada pela psicanálise numa instituição de saúde voltada para a população trans, tomando como central o conceito lacaniano de demanda. Queremos com isso delinear as expectativas que cercam este trabalho, tanto do lado institucional quanto do lado do paciente; bem como apresentar uma proposta ética de como lidar com tais demandas.

O artigo divide-se em dois momentos. Inicialmente será apresentado o que se está aqui entendendo como fenômeno trans, tentando fornecer uma definição do fenômeno que permita 
escapar tanto da abordagem limitada dos manuais classificatórios quanto das perspectivas em psicanálise que o atrelam a uma estrutura clínica determinada. Num segundo momento, propõe-se um debate sobre a prática clínica que nos trouxe essa população, apresentando nossos questionamentos sobre um trabalho com a demanda, aqui entendida no duplo sentido: tanto da instituição quanto do paciente.

\section{Fenômeno trans: o problema de sua definição}

Importa discutir inicialmente o que se está chamando aqui de vivências trans. Poderíamos qualificá-las apenas como o desejo de passar para o sexo oposto? Ou para caracterizá-las seria necessária a decisão de modificar a aparência, a realidade do corpo? Intervenções apenas estéticas são suficientes para se configurar uma vivência trans? Recorremos aqui ao documentário Laerte-se (Côrte, Vianna, Brum \& Silva, 2017), no qual a famosa cartunista, ao se perguntar sobre colocar ou não um implante mamário, afirma que busca responder a quatro verbos: "quero, posso, devo, preciso?" A partir de sua decisão de não colocar próteses, Laerte questiona o lugar que têm essas intervenções no corpo para essa população, criticando a ideia de que alguém seria mais ou menos trans por ter feito alguma cirurgia ou hormonioterapia.

Considera-se, neste trabalho, que o sentimento de desacordo entre o sexo biológico e o reconhecimento do corpo sexuado pode ser considerado uma vivência trans quando aquele que vive o conflito busca passar para o outro gênero, mesmo sem se submeter a grandes intervenções modificadoras do corpo. Ou seja, consideramos que o uso de vestimentas, cortes de cabelo, acessórios já pode configurar essa experiência. Sem julgarmos se alguém é mais ou menos trans, como aponta Laerte.

\section{A especificidade da demanda trans}

O trabalho no SUS que visa atender à população trans em relação ao processo transexualizador está regulamentado pela Portaria 2803/2013 do Ministério da Saúde (MS, 2013), que veio ampliar a Portaria 457/2008 do mesmo Ministério (MS, 2008), a qual não previa cirurgias. Estas são diretrizes recentes que visam orientar um trabalho também novo, mas que atendem a uma situação não tão nova assim. Se há alguma novidade nos pedidos de hoje, o novo não está exatamente em querer passar para o outro sexo, ou sequer na tentativa de atender a essa demanda.

Se o fenômeno não é novo, há, contudo, algo de inédito na forma de encaminhamento dessa demanda. Como nos aponta Márcia Arán (2006):

a fundamentação deste fenômeno na atualidade está baseada em dois dispositivos distintos. O primeiro diz respeito ao avanço da biomedicina na segunda metade do século passado principalmente no que se refere ao aprimoramento das técnicas cirúrgicas e ao progresso da 
terapia hormonal - que faz do desejo de "adequação" sexual uma possibilidade concreta. O segundo concerne à forte influência da sexologia na construção da noção de "identidade de gênero" como sendo uma "construção sociocultural", independente do sexo natural ou biológico (Arán, 2006, p. 50).

Tanto os avanços da tecnologia quanto o advento das teorias de gênero como construção social são fatores responsáveis por dar uma feição nova ao fenômeno trans, já que as mudanças no real do corpo tornaram-se não só empiricamente realizáveis como também validáveis simbolicamente pela ciência. Acrescente-se a isso o fortalecimento da ideia do acesso ao direito de cada um, com base no princípio de dignidade do ser humano, que implica a hipótese da autonomia do sujeito. Ressalte-se aqui que tal princípio levou determinadas construções teóricas a afirmar que a convicção subjetiva deve bastar por si só como critério para o atendimento da demanda trans. Esse tipo de abordagem critica a ideia de uma avaliação diagnóstica dessa demanda, por supor que o diagnóstico se reduz a uma série de etiquetamentos, consequentemente leva o paciente a sofrer uma violência pela equipe de saúde (Arán, 2006; Borba, 2014).

Apesar de estarmos de pleno acordo em relação à necessidade de acolhimento social à população trans, colocamos em dúvida o critério da convicção subjetiva, já que questionamos o quanto se pode estar seguro dela. Principalmente porque já acompanhamos de perto casos de destransições de gênero com todas as suas complicações. Por isso julgamos essencial sustentar uma direção de trabalho conforme a ética da psicanálise e interrogar essa demanda trans (como cabe ao analista frente a qualquer demanda). Isso não significa colocar em dúvida o que hoje tem se chamado de lugar de fala (Ribeiro, 2019) do sujeito, mas antes investigar se há uma divisão subjetiva; pois a Psicanálise pressupõe que o lugar de fala não se reduz àquilo que a consciência acredita saber.

O problema é que, ao solicitar ajuda médica, a pessoa trans passa a se submeter a essa ordem médica, a qual possui parâmetros que distinguem o normal e o patológico. De acordo com os SOC 7 (Standards of Care 7) da World Professional Association for Transgender Health (WPATH, 2012), é preciso ter um diagnóstico de disforia de gênero, de preferência primário (ou seja, que não seja consequência de outro diagnóstico), para se ter acesso a um tratamento para ela. O que gera uma tensão inevitável, pois aquilo que o paciente solicita coloca-o num lugar - o de doente - no qual ele não quer estar, mas cujos benefícios deseja, a saber: seu tratamento e seu reconhecimento. Tratamento que Ihe entregará os fármacos, as cirurgias, enfim, a possibilidade de uma transição.

Mas como nos situamos nisso como psicanalistas? Estamos inseridos numa lógica institucional, a qual, por sua vez, está submetida à ordem médica. Por se tratar aqui de um diagnóstico médico, sua elaboração é feita a partir de um conjunto de sinais e sintomas verificáveis; sendo sinal aquilo que pode ser objetivamente observável e sintoma o que é subjetivamente constatável pelo paciente. Porém, ainda que haja alguma escuta da narrativa subjetiva pela medicina, as entrevistas nesta clínica 
visam a presença ou ausência de determinados elementos que sirvam para construir o diagnóstico. Tais elementos possuem valor de confirmar ou infirmar a hipótese de uma categoria diagnóstica dada.

Neste ponto, importa assinalar a enorme diferença entre os diagnósticos psicanalítico e psiquiátrico/médico. A concepção diagnóstica dos manuais psiquiátricos é empirista, pois entende o transtorno como um conjunto de elementos ligados por mera contiguidade. Não por acaso, a frequência estatística com que esses elementos aparecem vinculados torna-se o critério de delimitação da categoria. Já para a psicanálise, um elemento jamais pode ser pensado desconectado de todos os outros, pois há uma lógica que preside à sua concatenação. Uma classe diagnóstica nunca é uma coleção de elementos desligados uns dos outros, sua vinculação nunca é arbitrária, desde que se possa demonstrar o sentido que cada fenômeno tem na estrutura. Isso só é possível mediante uma escuta que tenha como ponto de mira o sujeito.

No trabalho com a população trans, observamos as repercussões negativas de um discurso que visa apenas repertoriar sinais e sintomas. Na maioria das vezes, as equipes estão na busca de "certos elementos legitimadores da transexualidade como digna de atenção médica" (Borba, 2014, p.20). O mesmo raciocínio opera por parte daqueles que buscam o serviço, devendo, então, convencer a equipe de que satisfazem os critérios necessários para terem direito a uma cirurgia, "reatualizando, portanto, os sistemas de conhecimento científico que os patologizam" (p.20). A equipe pouco a pouco passa a não mais encontrar com o paciente, mas com um discurso próprio, abolindo tudo o que nele não possa se inscrever; e impedindo que o paciente possa de fato ser escutado a partir de seu saber sobre si mesmo. O discurso médico acaba fazendo o papel inverso ao da psicanálise, pois deve poder transformar os significantes do sujeito em signos médicos, perdendo o caráter de significante que representa um sujeito para outro significante (Clavreul, 1983).

Contudo, o psicólogo, nesse contexto, está também submetido à ética da psicanálise, o que faz uma diferença importante. Sendo necessário um outro critério para ocupar esse lugar, critério que exige fazer alguma conciliação entre o que é dessa ordem médica e da psicologia sem abrir mão da psicanálise. Como?

\section{A psicanálise e a oferta de escuta nesse ambiente}

O psicólogo clínico é um profissional de saúde mental e parte das suas obrigações é responder a solicitações, posicionando-se inclusive através da emissão de alguns documentos. Amparando esse fazer, há uma série de normativas que nos orientam. Considerando todas essas recomendações, entendemos que não é possível a alguém que se submeta à psicanálise e que se proponha a operar com ela que simplesmente aplique essa normativa em sua clínica. A ética da psicanálise nos adverte da impossibilidade de responder se estamos diante de um "verdadeiro" transexual, ou se há disforia de gênero associada a uma variabilidade de gênero verdadeira, ou mesmo se há um pedido verdadeiro de qualquer coisa... O psicanalista sabe que é impossível impor um critério de verdade exterior ao sujeito. 
Um ponto sensível que aparece toda vez que um psicanalista se propõe a falar da transexualidade é justamente o fato de a psicanálise trabalhar também com um tipo de diagnóstico, o que leva alguns a acusarem-na de colaborar com a estigmatização daqueles pacientes. Por isso é preciso deixar claro que nossa disciplina não trabalha com a noção de normalidade; ora, se não existe um sujeito normal, evidentemente não poderia existir os que desviam da norma. Nisso incorporamos os ensinamentos preciosos de Canguilhem (2009) que, em seu livro O normal e o patológico, critica a noção de normalidade como sendo pré-científica e carregada de conotações morais.

Por que então Freud e Lacan utilizam termos do campo da psicopatologia? Patologia aqui expressa o fato de que todos nós experimentamos dificuldades em nossa relação com a sexualidade e a morte. Não há um método correto ou adequado para lidar com isso que há de mais real na condição humana. Caso houvesse, aí sim, a noção de normalidade poderia encontrar alguma justificativa plausível. "Para Freud, a patologia é um sintoma que denuncia a verdade da constituição psíquica, ou seja, denuncia o estofo do qual é feito o psiquismo humano e sua grande complexidade" (Alberti, 2005, p. 347). As estruturas clínicas - neurose, psicose e perversão - designam lógicas de funcionamento distintas, que expressam diferentes formas de lidar com o real. O desconforto pelo fato de termos um corpo é uma das formas de emergência do real, que surge como tema central na clínica trans.

Não foi por acaso que usamos nesse trabalho a expressão fenômeno trans. A ideia é que tal fenômeno poderia estar presente nas 3 estruturas, evidentemente com funções e sentidos totalmente distintos em cada uma. Tomando como ponto de partida o fato de que o desconforto do sujeito com o próprio corpo sexuado é algo que se impõe a qualquer sujeito, são nítidas as diferenças no modo de tratar a questão dentro da lógica de cada estrutura. Um neurótico, em geral, nunca se sente garantido em sua identidade de homem ou mulher, a tal ponto de se atormentar intimamente por não possuir uma carga suficiente de virilidade ou feminilidade. O neurótico pode até acreditar no seu pertencimento a um determinado gênero, o que não o impede de colocar em dúvida e questionar diretamente o fundamento de sua identificação ao sexo. Na perversão, há um modo habilidoso de desconhecer a falta de ancoragem de sua identificação sexual: são sujeitos que constantemente se esforçam por se apresentar aos outros como mestres da satisfação, de tal forma que eles deslocam a falta de fundamento para fora de si mesmos. Já para um psicótico, uma forma possível de emergir a questão quanto à sua identidade sexuada seria uma certeza sem equívoco, que recusa sua inscrição no campo do Outro.

Lacan (1971/2009), no Seminário XVIII, ao se referir a Robert Stoller (1984) em seu livro Sex and gender, afirma que nunca teria chegado aos ouvidos deste a foraclusão lacaniana. Em função dessa frase, a transexualidade vem, desde então, sendo associada à psicose no campo lacaniano. Contudo, se insistirmos nesse passo e, antes de uma escuta, quisermos estabelecer um diagnóstico estrutural a priori, estaremos fora da psicanálise e sua ética. 
Se a psicanálise trabalha com o diagnóstico, não é com o intuito de rotular, estigmatizar ou segregar o paciente. 0 diagnóstico estrutural só se faz em transferência e tem por função orientar o analista na direção do trabalho analítico, já que existem intervenções que são possíveis em uma estrutura, mas seriam inúteis ou prejudiciais em outras.

E assim, advertidos disso, submetidos a essa lógica, recebemos pedidos de nossos pacientes e da instituição. Cientes disso, fazemos um juízo que só pode ser ético. Um juízo sobre o que escutamos do pedido endereçado à instituição, ao dito profissional de saúde mental. Existe a exigência legal de dois anos de acompanhamento do paciente para a emissão de um parecer quanto às cirurgias. Porém, os protocolos não estipulam qual a frequência deste acompanhamento, nem mesmo em que modalidade de encontros. Deveria esse acompanhamento ser individual ou em grupo? Com qual frequência? Semanal, mensal, bimestral, semestral? Não há nenhuma regulamentação sobre isso.

Ao acompanhar, em que uma equipe de saúde poderia se ancorar para dizer o que é a prerrogativa social de ser mulher ou de ser homem? Até onde entendemos, elas não estão dadas de antemão. É justo aí que se apoia nosso questionamento. Pois quando alguém diz, "sempre fui feminina", podemos querer saber o que é isso para aquele sujeito. Uns respondem afirmando que sempre gostaram de cozinhar e cuidar da casa; com o que podemos nos espantar, afinal quem disse que isso é feminino? Jamie Oliver é um grande cozinheiro! Alguém questiona se é homem? Outros, muito masculinos, também cuidam da casa, e ainda dizem: "minha mulher é bagunceira, homem é mais organizado e metódico". O que pode ser um espanto novamente. Afinal, onde isso está ancorado? Na história e na novela familiar de cada um. A cultura nos dá certos parâmetros, mas ainda assim, não garante a interpretação singular de cada pessoa.

Ao longo desses dois anos, é possível extrair junto com o sujeito, no trabalho a partir de sua demanda, como se deu a escrita inconsciente, aquilo que o situa na trama de sua vida. Interrogando como foi a construção daquele corpo, em que medida o reconhece ou o rechaça. Como foi a edificação daquela identidade, com suas peculiaridades, preferências, gostos e desgostos. E de onde saiu aquele nome? Afinal, é muito diferente ter um nome desde o nascimento, a partir do qual se fez o acesso ao mundo das palavras; e ter um nome escolhido depois, uma nomeação que não veio do outro, nem necessariamente do Outro; teria vindo de onde?

Pela experiência no CPATT, verifica-se que esse tempo não precisa ser de dois anos. Esse acompanhamento nunca é obrigatório, compulsório; sequer é possível obrigar alguém a vir e, em vindo, a estar ali verdadeiramente. Mas enquanto estiver ali, num trabalho de escutar e escutar-se, apostamos que não seja para cumprir um protocolo. E isso é o máximo que podemos diante da demanda. Não podemos atendê-la, nem podemos sustá-la. No final das contas, quem faz o trabalho de prescrever hormônios é o médico, quem opera é o médico; por outro lado, quem, de fato, se submete às intervenções é o paciente, é ele quem decide tomar ou não as drogas, operar-se ou não. Ele pode fazê-lo mesmo sem o aval de uma equipe. Quantos pacientes já não se hormonizavam antes de chegarem ao serviço? Muitos! Quantos não se injetaram silicone industrial e se submeteram a 
várias cirurgias sem qualquer parecer? Muitos também. Assim, não nos cabe coisa alguma frente a essa demanda, senão acolhê-la e trabalhar com ela.

Quanto à elaboração dos documentos, temos esse tempo para conhecer essa demanda e fazer um juízo. Caso nosso paciente não fique dois anos, temos um impedimento, no mínimo, burocrático que não nos permite a entrega do parecer. Caso o paciente venha e não se construa um laço de trabalho, também não é possível a elaboração de um parecer, afinal, nos basearíamos em que? Para emitir um juízo sobre algo, é preciso ter onde fundamentar esse juízo. E não serão os manuais ou livros que fundamentarão um pedido de intervenção no corpo de alguém, mas a escuta de sua própria história.

Nesses acompanhamentos verificamos, dentre outras coisas, a possibilidade de construção de laço do usuário com o serviço, com o profissional que o acompanha e a possibilidade de transmitir sua intenção com relação ao tratamento. Qualquer resposta a essa demanda é delicada, não apenas para o clínico, mas principalmente para o sujeito, pois em qualquer saída, encontra-se com a falta. Com a parcialidade da satisfação, da representação, de ser. Em nenhuma saída encontrará uma solução que concretize um ser sem falha.

\section{Vinhetas clínicas}

A chegada ao serviço não é necessariamente um pedido direcionado à psicologia, muito menos à psicanálise. Às vezes é só um pedido de acesso ao processo transexualizador. Por vezes recebemos alguns pedidos bem diretos: quero transicionar. Eu me sinto neste ou naquele gênero e quero ser lido/a assim. Apresentamos a seguir três situações clínicas cujo ponto de partida é parecido, mas cujos desfechos são distintos; o que indica como o trabalho com a demanda pode levar a uma ressignificação desse pedido inicial. Ressignificação não significa necessariamente desistir de fazer a transição, mas uma nova posição frente àquilo que se pedia - que pode ser, por exemplo, uma decisão em que o sujeito esteja mais advertido dos seus limites e possibilidades de suportar o que pede. Isso pode ocorrer no melhor dos casos, pois nem sempre há uma abertura ao trabalho.

Três sujeitos chegam ao serviço em momentos distintos com um pedido muito semelhante: gostariam de fazer a transição; o que os impede é um certo receio quanto ao julgamento da família.

\section{Caso 1:}

Andy chega pedindo uma mudança no corpo e principalmente nos documentos, mas faz a ressalva: "Não quero ser mais um LGBT sem lugar, sem estudo, sem nada nem ninguém. Eu amo minha família e quero que me aceitem, quero estudar, ter uma profissão. Então, antes de qualquer ação mais concreta quero saber como falar disso com eles". Vem regularmente. Fala da família, dos namoros, dos estudos. Sabia que era importante estar do lado masculino da vida, sem saber dizer o 
que mesmo isso representava na sua vida. Seu nome de registro Andréa era quase o nome do pai (André), apenas uma letra a mais para o bebê. Na adolescência começou a se fechar e, com as mudanças no corpo, mal podia manter o contato com a família; brigava muito com o irmão, mesmo sabendo que o amava e admirava; afastou-se dos pais. Começa a poder falar de uma diferença entre o masculino e o feminino pela via da oposição entre: tarefas domésticas e disposição do lado das mulheres, força e postergação do lado masculino. Vinha situando seu lugar nessa trama familiar por cerca de meio ano. Usava o apelido como nome social com os amigos, começava a pensar em namorar com mulheres, vislumbrava a possibilidade de conversar em casa sobre ser LGBT. Muitos ensaios depois, finalmente o fez, deixando claro a todos sua posição; teve sua acolhida, seu aceite. Seguia num trabalho sobre como seria uma transição, até que começou a questioná-la. Cerca de um ano depois do início do tratamento, repetindo uma pergunta que a analista lhe fazia constantemente desde sua chegada, ela disse: "sabe, isso tudo foi uma grande briga com o feminino". A pergunta da analista à que Andy se referira era a seguinte: Andy sempre dizia que o masculino lhe fazia bem, que só de se saber desse lado do leque já estava bom, e que, por isso, precisava passar para lado masculino, talvez só um nome bastasse. A analista então perguntara: o que mesmo você chama de masculino e feminino?

Andy nunca tomou hormônios, não trocou suas roupas que sempre foram andróginas, nunca mudou o cabelo que era colorido - rosa, roxo, verde, azul ou laranja. Mas pôde se perguntar pelo seu corpo, pelo que entendia por masculino e feminino, por amor, sexo e família. Não havia propriamente uma resposta; aliás, resposta alguma colocaria a trabalho, ou modificaria a posição assumida diante da vida. A reflexão Ihe fez nomear sua demanda, interrogá-la e derivá-la, apaziguando-a consigo mesma. Andy se deu conta de que, em seu caso, querer passar para o lado masculino do mundo representava uma briga com o feminino, com a diferença sexual. Mas ela não pôde continuar a se perguntar, seu consentimento em se questionar foi até ali.

Esse pequeno trecho do caso deixa como pergunta o alcance de um trabalho numa instituição. Costumamos dizer que, numa instituição, não se faz análise, mas o trabalho de Andy era mesmo muito rente ao analítico. Havia uma grande habilidade de se interrogar, de tomar a sério as perguntas e de se implicar, mas havia algo do sexual que ainda não podia se mostrar. Não apenas ali, no trabalho analítico; havia algo do sexual que ainda não havia se mostrado para Andy na vida. Como se não tivesse ainda se encontrado com o corpo mesmo, com o avassalador da pulsão sexual. Resta a questão: será que realmente se apaziguou com seu sexo? Foi embora ao concluir que não precisava de uma transição, quando parecia prestes a dar início a uma análise propriamente dita. Teria sido diferente em outro espaço?

\section{Caso 2:}

O mesmo aconteceu com Mateo. Pedia pela transição, mas havia algum receio com relação à família, perguntava-se sobre o que poderiam vir a pensar. Ele tomara a decisão de sair da casa dos 
pais e mudou-se de cidade. Havia questões afetivas que eram segredos, não podiam ser ditas, nem à analista; trazia os imbróglios nas relações cotidianas, sempre desencontradas, nos diversos espaços que ocupava. Vivia em uma situação bem difícil, sempre sem dinheiro, sem trabalho, poucos amigos, indo mal na faculdade. Odiava sua voz, que achava muito feminina. Odiava parecer uma menina, odiava a faculdade que estava cursando, odiava o lugar onde morava, mas não podia voltar pra casa dos pais, a quem também odiava. Enfim, odiava. Começou falando desse ódio tão grande e foi paulatinamente se organizando; passou a ir bem na faculdade, arrumando amigos, morando melhor, ganhando algum dinheiro. A vida ia melhorando e restava a raiva contra o feminino, principalmente com a voz. Pedia, quase exigia os hormônios, sem poder explicar que diferença supunha que isso faria; imaginava que a solução para seus impasses viria junto com a hormonização. A barreira à sua felicidade era agora posta por ele em algo externo, na opinião da família, no julgamento dos pais. Sua briga foi gradualmente se restringindo a esse espaço, já não se estendendo de forma sistêmica às outras relações a essa altura do tratamento. Isso Ihe permitia cuidar da vida, trabalhando e estudando sem grandes crises de angústia.

Contudo, após uma viagem à casa dos pais, não consegue mais seguir se questionando e vai pedir a transição ao médico. Parte do seu conflito estende-se então para a instituição. Afirma ter receio quanto à transição, avisando que ainda há algo por ser investigado. A analista comunica ao profissional médico suas reticências quanto à realização da transição naquele momento. Diz ainda a Mateo, "pelo que você diz, isso não parece que vai resolver seu problema. Por que essa súbita urgência?" Apesar disso, Mateo decide junto com o médico iniciar a hormonização. Começa. Na sequência, para de falar. Vem às consultas e fica na sala em silêncio, nem dirige o olhar à analista. Pergunto, questiono. Nada. Fica visivelmente mal, emagrece, mostra-se relapso com a higiene. A equipe começa a perguntar à analista o que está acontecendo com ele. Deixa de vir. Depois de um tempo volta, diz finalmente que tem um problema com a analista, ao que se recomenda que busque outra psicóloga. Ele não quer mais psicólogas, e diz que não pode mais falar. Para de vir ao serviço. Oito meses depois do início do tratamento hormonal, interrompe o uso dos hormônios. Adoece, não come, não dorme. Vem à analista dizer que não pode mais falar. A equipe médica se reúne e decidem recomendar retomar o uso do hormônio, que tocaria de alguma forma a disforia, que teria aumentado muito. Mateo some.

A analista se interroga sobre o que já estava lá nos últimos encontros, o que não podia ser dito sobre a família e que agora havia espraiado um silêncio mórbido pela sua vida. Algo que fica claro quando ele dizia não poder escutar sua voz, agora mais grave, mas ainda "meio de pato", nem de homem, nem de mulher. Ainda odiava a voz, mas não era mais a sua voz, era um som que não podia reconhecer como seu. Não falava. E quando incitado a falar, dizia que não podia falar nem ali, nem em canto algum. A analista se indaga sobre o problema que havia com a voz. Houve um erro na direção? É possível que sim; talvez o trabalho analítico pudesse tê-lo levado a colocar um ponto de suspensão na sua decisão. Mas após a viagem, o trabalho tomou um novo rumo e não pudemos saber 
o que houve. O fato é que a transição foi feita de forma muito precipitada, sob o efeito de um encontro desastroso com a família, que o levou a uma desesperada passagem ao ato. A hormonização se deu sem que o sujeito tivesse condições de arcar com tamanha transformação naquele momento: se a sua voz era insuportável, ele a trocou por outra que lhe era ainda mais estranha.

\section{Caso 3:}

Samuel faz um pedido semelhante ao dos outros dois pacientes: quer a transição, mas tem muito receio sobre como a família vai tomar isso, pois não quer perdê-los. Afirma ter episódios de crise intensa com o corpo; afirma sentir uma dor intensa, espalhada pelo corpo, visivelmente angustiado. Parece estar dizendo não a tudo, à faculdade, à família, ao corpo. Suas crises se intensificam. Chora muito e quer prontamente se livrar de tudo isso que the causa tanto sofrimento, mas que mal consegue situar onde está: se no contato com os familiares, no corpo, na voz. Afirma não estar em paz em lugar algum e que se assusta ao escutar o nome social, que escolheu quando chegou ao serviço. A analista diz muito prontamente que está receosa com esse início de sua transição, recomendando ao paciente que aguarde um pouco. Pergunta se Samuel aceita que ela tome uma posição contrária à sua transição, por não estar de acordo que ele inicie a transição já, nem mesmo que use o nome social. Inicialmente o paciente reage quase com um choque e, pouco depois, aparenta alívio. Apenas olha a analista, sem discordar. A analista diz que está escutando que talvez o processo possa acontecer mais devagar, depois de mais reflexão. Os dois vão juntos até a recepção, o nome social do paciente é retirado, a analista diz que é uma recomendação dela e Samuel afirma estar de acordo. A analista escreve no prontuário que o paciente não pode ser encaminhado ao médico, nem tomar hormônios, assumindo para si essa responsabilidade quanto à parada na transição, que ainda não podia ser assumida pelo paciente. $O$ impedimento é acolhido pela equipe.

A partir dessa intervenção, Samuel passou a trabalhar intensamente. Construiu sua história, pôde revisitar os impasses com o corpo e a ligação disso com fatos marcantes da infância, a relação disso com sua forma de se expressar, sua arte. Repensou a faculdade escolhida e o impasse com o tal curso, foi acolhido na universidade. Pôde falar inclusive sobre a escolha do nome, e como tirou da Isabela um Samuel. Trabalhou no sentido de viabilizar sua transição, que começou quase um ano depois da sua chegada ao serviço. Agradece constantemente o freio que veio de fora - "que bom que você não me deixou tomar hormônios logo" -, segurando-o concretamente com relação à hormonização, mas, principalmente, simbolicamente, ao dar sustentação ao trabalho que ele tinha pela frente, mantendo a pergunta sobre seu sofrimento com a vida, construindo junto com o paciente um estofo significante que lhe permitisse sustentar suas ações. Fez sua transição, podendo refletir a cada passo, construindo seu modo de transicionar e de se fazer presente no mundo. Tem dois anos de transição, documentos retificados, aguardando retirada das mamas.

Todos esses casos apontam para a necessidade de refletirmos sobre o papel da acolhida dessa demanda. Suspender a ação frente a um pedido é possibilitado ao psicanalista por conhecer a 
impossibilidade de satisfação na sua concretização. O humano sofre por ser determinado por uma estrutura de linguagem e a demanda apenas veicula essa mensagem cifrada (Lacan, 1957-58/1999). Não se trata para o psicanalista de dizer sim ou não à demanda, mas de poder fazer com que o sujeito possa responder pelo seu pedido.

$\mathrm{O}$ ato de responder implica vários momentos. No caso de Mateo, sua decisão se deu num instante de ver, sem que ele tivesse podido verificar suas condições para sustentar seu ato na posterioridade. Já os casos de Andy e Samuel mostram que foi possível a eles passar pelo instante em que percebem sua incerteza quanto àquilo que pediram, propiciando um tempo de elaboração que se conclui de formas muito distintas, já que Andy desiste da transição, ao passo que Samuel a leva em frente. O importante aqui é que não se trata, para ambos, da mesma posição do ponto de partida. Andy não é mais aquele sujeito que, desejoso de fazer a transição, via-se frustrado pelos obstáculos externos, já que agora ele desistiu verdadeiramente. Do mesmo modo, no final do processo, Samuel pôde decidir a mesma coisa que pedia inicialmente, mas não o fez da mesma maneira. Ainda quer mudar o corpo e seu nome, mas já não está acuado diante da vida, pode tomar para si o trabalho de construí-la.

O trabalho com a demanda visa tanto permitir ao sujeito verificar se ele tem condições de arcar com as consequências daquilo que pediu quanto elaborar um modo de sustentar-se em sua decisão, qualquer que ela seja. Por isso, entendemos que a ressignificação implica sempre que o sujeito possa se ressituar em relação a seu pedido inicial.

O processo de transição não se dá exclusivamente pela via dos hormônios ou da cirurgia, mas apenas quando ela (a transição) tem um lugar na vida do sujeito. Assim, a função de uma avaliação inicial não é dizer algo sobre alguém, mas poder levar alguém a dizer de si, a se escutar e a decidir com responsabilidade sobre si mesmo. Mas, para isso, há que se fundar um lugar de trabalho, e uma confiança nesse trabalho. Lugar que ainda estava sendo fundado com Mateo e que não pode se concretizar.

\section{Conclusão}

O trabalho com a demanda na clínica trans possui algumas especificidades, já que tais pacientes pedem ao Estado e à ordem médica que realizem em si uma intervenção que envolve grandes consequências para seu corpo e para seu senso de identidade pessoal e social. 0 paciente é levado aqui a se submeter a uma ordem que avalia sua demanda em termos que são estranhos à forma como ele mesmo compreende seu pedido. No caso da medicina, sua demanda é julgada em termos de saúde ou doença, tendo o paciente que provar ser portador de uma patologia a fim de conseguir um tratamento. No caso do Estado, sua demanda é também avaliada em termos dos custos econômicos.

A avaliação da demanda a ser feita por um psicanalista é de natureza muito distinta, já que não se trata de avaliar segundo critérios exteriores ao sujeito, que independam de seu consentimento. 
A avaliação do analista nunca é puramente objetiva, ela visa incluir o sujeito nessa avaliação, posicionando-se diante de sua própria demanda.

Tal lembrança é importante, pois a transexualidade e a travestilidade são hoje fatos da cultura, que proporcionam aos sujeitos três importantes pontos de ancoragem: uma nomeação, que Ihes permite saber como se localizar frente aos outros grupos no mundo social; uma identificação, que lhes permite até certo ponto a codificação de seus modos de convívio entre iguais; e um reconhecimento pelo Estado, que Ihes permite uma organização coletiva em prol de seus interesses. Porém, por mais importante que seja para o sujeito a sua inscrição nesse movimento, não se deve desprezar também seu esforço de medir a distância que o separa do grupo, construindo sua forma singular de existir nesse espaço. Dar voz ao sujeito como aquele que pode responder pela singularidade de seu lugar é o que pode uma psicanálise oferecer de melhor.

É muito comum na comunidade trans escutar que pessoas cis não podem falar sobre a realidade trans, já que não passaram por essas experiências. Porém, a clínica com os sujeitos trans nos leva a questionar a ideia de uma realidade trans única. Existe apenas um único jeito de ser trans? Pode então, alguém ser mais trans que outro alguém? Por acaso existe ' $A$ ' realidade cis e ' $A$ ' realidade trans? Alguém vai um dia poder dizer toda essa verdade sobre o que é ser um homem ou uma mulher? Pensamos que não. E por discordar dessa ideia de unicidade trans, dizemos que as pessoas trans devem ser ouvidas, devem poder falar de si e da sua realidade, ter sua fala valorizada, respeitada. Não chegaremos a uma única verdade. A realidade é psíquica, de cada um, portanto. Sempre e a cada vez.

\section{Nota:}

1. O artigo se baseia na dissertação de mestrado defendida por Esther Siza Tribuzy no Programa de Pós-graduação em Psicologia da Universidade Federal do Paraná / UFPR, em 2019. A pesquisa de mestrado foi financiada com bolsa da CAPES.

\section{Referências Bibliográficas}

Alberti, S. (2005). A perversão, o desejo e a pulsão. Revista Mal Estar e Subjetividade, 5(2), 341-360. Recuperado de http://pepsic.bvsalud.org/scielo.php?script=sci_arttext\&pid=S1518$61482005000200008 \& \operatorname{lng}=p t \& t \operatorname{lng}=p t$

Arán, M. (2006). A transexualidade e a gramática normativa do sistema sexo-gênero. Ágora: Estudos em Teoria Psicanalítica, 9(1), 49-63. Recuperado de http://www.scielo.br/pdf/agora/v9n1/a04v9n1.pdf

Borba, R. (2014). (Des)aprendendo a ser. Trajetórias de socialização e performances narrativas no processo transexualizador. (Tese de doutorado). UFRJ, Rio de Janeiro, Brasil. 
Côrte, A. \& Vianna, C. (produtoras) \& Brum, E. \& Silva, L. B (diretoras). (2017). Laerte-se. Brasil: Netflix.

Canguilhem, G. (2009). O normal e o patológico. Rio de Janeiro: Forense Universitária.

Clavreul, J. (1983). A ordem médica: poder e impotência do discurso médico. São Paulo: Editora Brasiliense.

Lacan, J. (1999). O Seminário, Livro 5: As Formações do Inconsciente. Rio de Janeiro: Jorge Zahar Editor. (Trabalho original publicado em 1957-1958).

Lacan, J. (2009). O Seminário, Livro 18: De um discurso que não fosse semblante. Rio de Janeiro: Jorge Zahar Editor. (Trabalho original publicado em 1971).

Ministério da Saúde (2008). Portaria MS no. 457, de 19 de agosto de 2008. Regulamentação do processo transexualizador no âmbito do Sistema Único de Saúde(SUS). Recuperado de http://bvsms.saude.gov.br/bvs/saudelegis/sas/2008/prt0457_19_08_2008.html.

Ministério da Saúde (2013). Portaria MS no. 2803, de 19 de novembro de 2013. Redefine e amplia o processo transexualizador no Sistema Único de Saúde(SUS). Recuperado de http://bvsms.saude.gov.br/bvs/saudelegis/gm/2013/prt2803_19_11_2013.html

Ribeiro, D. (2019). Lugar de fala. São Paulo: SP.

Stoller, R. J.(1984). Sex and gender: the development of masculinity and femininity Londres: Karnac Books.

WPATH (2012). Normas de atenção à saúde das pessoas trans e com variabilidade de gênero. Recuperado de: https://www.wpath.org/media/cms/Documents/SOC\%20v7/SOC\%20V7_Portuguese.pdf.

Citação/Citation: Siza Tribuzy, E., Zétola Lustoza, R. (nov. 2020 a abr. 2021). A clínica psicanalítica frente à demanda trans. Revista aSEPHallus de Orientação Lacaniana, 16(31), 26-39. Disponível em www.isepol.com/asephallus. Doi: 10.17852/1809-709x.2021v16n31p26-39

Editor do artigo: Tania Coelho dos Santos.

Recebido/Received: 10/03/2020 / 03/10/2020.

Aceito/Accepted: 10/28/2020 / 28/10/2020.

Copyright: (c) 2019 Associação Núcleo Sephora de Pesquisa sobre o moderno e o contemporâneo. Este é um artigo de livre acesso, que permite uso irrestrito, distribuição e reprodução em qualquer meio, desde que o autor e a fonte sejam citados/This is an open-access article, which permites unrestricted use, distribution, and reproduction in any medium, provided the author and source are credited. 